\title{
Note
}

\section{The Sex Chromosomes of Silene latifolia Revisited and Revised}

\author{
Martina Lengerova,* Richard C. Moore, ${ }^{\dagger}$ Sarah R. Grant ${ }^{\dagger}$ and Boris Vyskot*,1 \\ *Institute of Biophysics, Academy of Sciences of the Czech Republic, CZ-612 65 Brno, Czech Republic and \\ ${ }^{\dagger}$ Department of Biology, University of North Carolina, Chapel Hill, North Carolina 27599-3280
}

Manuscript received March 26, 2003

Accepted for publication June 17, 2003

\begin{abstract}
Classical studies have established that, during meiosis, the $\mathrm{X}$ and $\mathrm{Y}$ chromosomes of the model dioecious plant Silene latifolia pair over a region at the ends of their q arms. We used fluorescence in situ hybridization of two molecular markers to demonstrate that this widely accepted model is incorrect. From these data we conclude that the homologous arm of the $\mathrm{X}$ chromosome is the $\mathrm{p}$ arm and that of the Y chromosome is the $\mathrm{q}$ arm. The establishment of the proper orientation of the pseudoautosomal region is essential for mapping and evolutionary studies.
\end{abstract}

$\mathrm{T}$ HE Silene genus is a popular model system to study the evolution of the sex chromosomes in plants. Many Silene species are gynodioecious (e.g., Silene noctiflora, S. vulgaris), while a few are hermaphroditic (e.g., S. conica, S. gallica) or dioecious (e.g., S. latifolia, S. dioica). Importantly, all these species have the same chromosome number, $n=12$. This offers the opportunity to trace the origins of the sex chromosomes by comparing the gene context of autosomes in nondioecious species with sex chromosomes in dioecious species. The correct number of chromosomes in S. latifolia Poiret (syn. Melandrium album Garcke or white campion) was first determined by STRAsburger (1910), although he did not note the presence of heteromorphic sex chromosomes. These were independently identified several years later by BlackbuRn (1923) and Winge (1923). Female plants are homogametic and possess two X chromosomes, whereas male plants are heterogametic, harboring one $\mathrm{X}$ and one larger $\mathrm{Y}$ chromosome.

Much attention has been paid to the study of the structure and sex-determining function of the sex chromosomes since their discovery (see recent reviews MATSUNAgA and KaWANo 2001; Negrutiu et al. 2001; Charlesworth 2002). Heat- or colchicine-induced polyploid plants and $\mathrm{Y}$ deletion mutants were used as tools for early studies of the structure and function of the sex chromosomes (WESTERGAARD 1940, 1946, 1958; WARMKE 1946). It was clear from these studies that the Y chromosome is required for proper male development,

\footnotetext{
${ }^{1}$ Corresponding author: Institute of Biophysics, Academy of Sciences of the Czech Republic, Kralovopolska 135, CZ-612 65 Brno, Czech Republic. E-mail: vyskot@ibp.cz

because no males without the $\mathrm{Y}$ are observed (WESTERGAARD 1948). Subsequently, it was determined that the $\mathrm{X}$ chromosome also plays an essential role in reproductive development. The presence of the X chromosome is necessary for embryogenesis (Veuskens et al. 1992) and for development of the female gametophyte (JANOuser et al. 1998). Three chromosomal regions containing sex-determining genes have been identified on the $\mathrm{Y}$ chromosome through analysis of $\mathrm{Y}$ chromosome deletion mutants: the female suppressor region [its deletion resulted in hermaphroditic flowers (WESTERGAARD 1946; LARDON et al. 1999)], the early stamen development region [deleting results in asexual flowers (FARbos et al. 1999) ], and the late stamen development region [deleting results in sterile male flowers (WESTERGAARD 1946) ]. In meiosis it was observed that the X and $\mathrm{Y}$ chromosomes pair at one of their ends. This region is called the pseudoautosomal region (PAR), and it was concluded that the $\mathrm{X}$ and $\mathrm{Y}$ chromosomes probably pair over their q arms. WestergaARD (1940, p. 36) wrote that: "In some cases it was possible to decide with certainty that the longer arm of the X-chromosome was always associated with Y." In his later articles WESTERGAARD $(1948,1958)$, provided a schematic sketch of the sex chromosomes (Figure 1A). This view of S. latifolia sex chromosome structure has survived a half century and has been generally accepted by the scientific community. It can be also found in many genetics textbooks (e.g., Gardner et al. 1991; Klug and Cummings 1991; GRIFFITHS et al. 1996). Up to now, however, no cytogenetic markers that could verify the orientation of sex chromosome pairing in S. latifolia have been described. A new era of Silene research began in the early 1990s, 



Figure 1.-Schematic of the $\mathrm{X}$ and $\mathrm{Y}$ sex chromosomes in S. latifolia. (A) Classical scheme of the structure of the $S$. latifolia sex chromosomes as presented by WESTERGAARD (1946). I, II, and III, differential parts of the Y chromosome (I, segment containing female suppressor region; II, segment containing genes that initiate anther development; III, segment containing genes that control later stamen development); V, differential part of the $\mathrm{X}$ chromosome. Pseudoautosomal regions (IV, VI) are indicated on $\mathrm{q}$ arms of both sex chromosomes. (B) Diagram of FISH hybridization signals on the sex chromosomes for the subtelomeric repeat probe, $\mathrm{X} 43.1$ ( ), and the sex-linked genomic probe, DD44 (O). We present a new model (C) of the sex chromosomes in S. latifolia. The PARs are hatched and are present on the $p$ arm of the $\mathrm{X}$ and the $\mathrm{q}$ arm of the $\mathrm{Y}$. Differential parts of the $\mathrm{X}$ (black) and $\mathrm{Y}$ (white) are indicated as in A. The relative size and arm ratios are in scale, but the length of the PAR is arbitrary.

with a renewed effort to understand the molecular genetics of sex determination of S. latifolia, as well as to comprehend the structure, function, and evolution of its heteromorphic sex chromosomes. Extensive karyotyping of metaphase chromosomes has revealed that both sex chromosomes, $\mathrm{X}$ and $\mathrm{Y}$, are metacentric (CIUPERCESCU et al. 1990; GRABOWSKA-JOACHIMIAK and JoAСНIміAк 2002). The $\mathrm{Y}$ chromosome possesses nearly equal arms (arm ratio, $r=1.09$; Ciupercescu et al. 1990), whereas it is possible upon visual inspection to identify the $\mathrm{p}$ and $\mathrm{q}$ arms of the $\mathrm{X}$ chromosome $(r=$ 1.44; Ciupercescu et al. 1990). More recent molecular cytogenetics studies have sought to identify molecular markers to be used for physical mapping of S. latifolia chromosomes using fluorescence in situ hybridization (FISH). One of the first of such markers identified was the subtelomeric repetitive sequence, X43.1 (Buzer et $a l .1997)$. This sequence hybridizes in situ to the subtelomeric regions of most of the autosomes and the $\mathrm{X}$ chromosome and to the subtelomeric region of the $\mathrm{q}$ arm of the Y chromosome. When hybridized to meiotic preparations, X43.1 was found on the same arm of the Y chromosome as the PAR (Buzek et al. 1997).

The hunt for sex-linked genes also began anew during the early 1990s. A number of research groups have used different approaches to search for sex-linked and/or sex-specifically expressed genes to elucidate the molecular genetics of sex determination in S. latifolia (DonNIson et al. 1996; Delichere et al. 1999). Moore et al. (2003) identified the sex-linked gene pair, DD44X/ $D D 44 Y$, by screening for Y-linked cDNAs isolated from a differential display between male and female premeiotic floral mRNAs. DD44 encodes a protein similar to the oligomycin sensitivity conferring protein, an essential component of the mitochondrial ATP synthase. Physical mapping placed this gene on the $\mathrm{q}$ arm of the $\mathrm{X}$ chromosome, but because both arms of the metaphase Y chromosome are hardly distinguishable in size, it was not clear which arm of the Y chromosome carries DD44. Genetic deletion mapping linked it to the female suppressing region (MoORE et al. 2003), which has been localized to the $\mathrm{Y}$ chromosome arm that does not carry the PAR (LARDon et al. 1999). Because classical cytogenetics studies (WeStergaARD 1940) place the PAR on the $\mathrm{q}$ arm of the $\mathrm{X}$ chromosome, these data suggested that $D D 44$ was found on opposite arms of the $\mathrm{X}$ and $\mathrm{Y}$ chromosomes. It was hypothesized that this rearrangement was due to either a chromosomal inversion or a segmental translocation on the Y chromosome (Moore et al. 2003).

To confirm that $D D 44$ physically mapped to the $\mathrm{Y}$ chromosome arm opposite the PAR, we performed bicolor FISH on metaphase chromosomes (Figure 2, A and B) prepared from protoplasts derived from the root tips of germinating seeds (HLAdilova et al. 1998). The two probes used were an 18-kb genomic clone containing the $D D 44 X$ allele and the X43.1 subtelomeric repeat sequence. In female metaphases we regularly observed clear DD44 signals in the distal regions of the $\mathrm{q}$ arm of both X chromosomes (Figure 2A). In male metaphases, DD44 also hybridized to the $\mathrm{q}$ arm of the $\mathrm{X}$ chromosome as expected (Figure 2B). However, in males, DD44 hybridized on the arm of the Y chromosome opposite that of X43.1 (Figure 2B), which is found on the same arm as the PAR (BUzEK et al. 1997). To confirm the localization of these markers with respect to the PAR, we prepared meiotic squashes of immature anthers at different stages of development and again performed bicolor FISH with the DD44 and X43.1 probes. This experiment confirmed the localization of X43.1 on the homologous arm (possessing PAR) of the Y chromosome and DD44 on the opposite arm (Figure 2C). Surprisingly, we observed a very clear DD44 hybridization signal on the nonhomologous arm (opposite the PAR) of the X (Figure 2C). Because DD44 localizes to the $\mathrm{q}$ arm of the $\mathrm{X}$ chromosome in mitotic preps, we conclude that the PAR is found on the opposite arm, or $p$ arm, of the X. A summary of the results of these experiments is illustrated in Figure 1B.

We present a revised vision (Figure 1C) of the S. latifolia sex chromosomes based on the results of these experiments. Contrary to WestergaARD's (1946) depiction of the sex chromosomes (Figure 1A), the PAR is located 

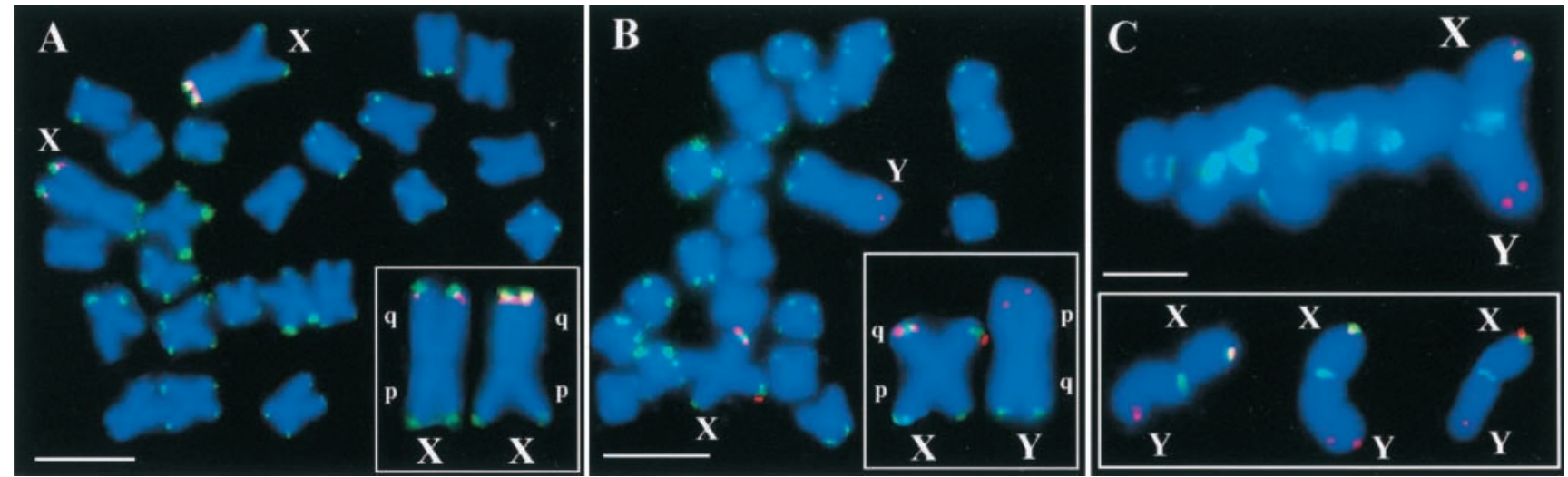

Figure 2.-Bicolor FISH using the subtelomeric repetitive sequence, X43.1, and the 18-kb genomic clone, DD44, on S. latifolia mitotic and meiotic chromosomes. FISH probes were labeled by nick translation using SpectrumGreen- or Cy3-conjugated nucleotides and are visualized as green (X43.1) or red (DD44) respectively (when merged the signals look yellowish on the X). Chromosomes were counterstained with 4',6-diamidino-2-phenylindole. In wild-type female (A) and male (B) mitotic spreads X43.1 hybridizes to the subtelomeric regions of most of the autosome pairs. On the sex chromosomes these signals are found on both arms of the X chromosome and only on the $\mathrm{q}$ arm of the Y chromosome. DD44 hybridizes to the distal part of the $\mathrm{q}$ arm of the $\mathrm{X}$ chromosomes and to the distal one-third region of the Y chromosome arm opposite the X43.1 signal. Insets in A and $\mathrm{B}$ show a detailed view of the sex chromosomes. The $\mathrm{p}$ and $\mathrm{q}$ arms of the sex chromosomes are indicated. (C) Chromosomes in metaphase I of meiotic division. X43.1 hybridizes to both arms of the X chromosome and to the homologous arm (PAR) of the Y chromosome. DD44 localizes to the differential arms of both sex chromosomes (opposite the PAR). The inset shows bicolor FISH of X43.1 and DD44 in more sex chromosome bivalents that are formed during meiotic division. Bars, $10 \mu \mathrm{m}$.

on the $\mathrm{p}$ arm of the $\mathrm{X}$ chromosome. Our new version forces us to change the interpretation of the relative positions of the $D D 44 X$ and $Y$ alleles of Moore et al. (2003). A structural rearrangement or translocation event involving the $D D 44 Y$ allele is no longer needed to explain why $D D 44 X$ and $Y$ are on opposite arms of the sex chromosomes. Now we conclude that both are on the differential arms of the sex chromosomes as expected if they evolved from the same single-copy gene on an ancestral autosome.

S. latifolia is a good model for the study of early events in sex chromosome evolution, as it possesses relatively young sex chromosomes (estimated age of 20 MYA; AtANAssov et al. 2001), in contrast to mammalian sex chromosomes, which evolved about 300 MYA (LAHN and PAGE 1999). The data presented here are especially important now, when new sex-linked sequences are being identified and mapped to the S. latifolia sex chromosomes. Our own experience mapping DD44 shows how important the proper knowledge of the orientation of the sex chromosomes is for correct interpretation of data relevant to the evolution of the sex chromosomes. It was shown in humans that the evolution of the $Y$ chromosome happened in a stepwise series of chromosomal inversions (LAHN and PAGE 1999). Now that we have developed molecular and genetic markers to distinguish the arms of the $\mathrm{X}$ and $\mathrm{Y}$ chromosomes, it should be possible to determine if such processes are occurring with the S. latifolia Y chromosome.

This study was supported by the Grant Agency of the Czech Republic (grants 204/02/0417 and 522/03/0354), the National Science Foundation (grant MCB-9816864), and the National Institutes of Health (grant F32 GM20891-01).

\section{LITERATURE CITED}

Atanassov, I., C. Delichere, D. A. Filatov, D. Charlesworth, I. Negrutiu et al., 2001 Analysis and evolution of two functional Y-linked loci in a plant sex chromosome system. Mol. Biol. Evol. 18: 2162-2168.

Blackburn, K. B., 1923 Sex chromosomes in plants. Nature 112: $687-688$

Buzek, J., H. Koutnikova, A. Houben, K. Riha, B. Janousek et al., 1997 Isolation and characterization of X chromosome-derived DNA sequences from a dioecious plant Melandrium album. Chromosome Res. 5: 57-65.

Charlesworth, D., 2002 Plant sex determination and sex chromosomes. Heredity 88: 94-101.

Ciupercescu, D. D., J. Veuskens, A. Mouras, D. Ye, M. Briquet et al., 1990 Karyotyping Melandrium album, a dioecious plant with heteromorphic sex chromosomes. Genome 33: 556-562.

Delichere, C., J. Veuskens, M. Hernould, N. Barbacar, A. Mouras et al., $1999 S l Y 1$, the first active gene cloned from a plant Y chromosome, encodes a WD-repeat protein. EMBO J. 18: 41694179 .

Donnison, I. S., J. Siroky, B. Vyskot, H. Saedler and S. Grant, 1996 Isolation of Y chromosome-specific sequences from Silene latifolia and mapping of male sex-determining genes using representational difference analysis. Genetics 144: 1893-1901.

Farbos, I., J. Veuskens, B. Vyskot, M. Oliviere, S. Hinnisdaels $e t$ al., 1999 Sexual dimorphism in white campion: deletion on the $\mathrm{Y}$ chromosome results in a floral asexual phenotype. Genetics 151: 1187-1196.

Gardner, E. J., M. J. Simmons and D. P. Snustad, 1991 Principles of Genetics. John Wiley \& Sons, New York.

Grabowska-JoACHIMIAK, A., and A. JoAchimiak, 2002 C-banded karyotypes of two Silene species with heteromorphic sex chromosomes. Genome 45: 243-252.

Griffiths, A. J. F., J. H. Miller, D. T. Suzuki, R. C. Lewontin and W. M. Gelbart, 1996 An Introduction to Genetic Analysis. W. H. Freeman, New York.

Hladilova, R., J. Siroky and B. Vyskot, 1998 A cytospine technique for spreading plant metaphases suitable for immunofluorescence studies. Biotech. Histochem. 73: 150-156.

Janousek, B., S. R. Grant and B. Vyskot, 1998 Non-transmissibility of the $\mathrm{Y}$ chromosome through the female line in androhermaphrodite plants of Melandrium album. Heredity 80: 576-583. 
Klug, W. S., and M. R. Cummings, 1991 Concepts of Genetics. Macmillan, New York.

Lahn, B. T., and D. C. PAGE, 1999 Four evolutionary strata on the human Y chromosome. Science 286: 964-967.

Lardon, A., S. Georgiev, A. Aghmir, G. Le Merrer and I. Negrutiu, 1999 Sexual dimorphism in white campion: complex control of carpel number is revealed by Y chromosome deletions. Genetics 151: 1173-1185.

Matsunaga, S., and S. Kawano, 2001 Sex determination by sex chromosomes in dioecious plants. Plant Biol. 3: 481-488.

Moore, R. C., O. Kozyreva, S. Lebel-Hardenack, J. Siroky, R. Hobza et al., 2003 Genetic and functional analysis of DD44, a sex-linked gene from the dioecious plant Silene latifolia, provides clues to early events in sex chromosome evolution. Genetics 163: 321-334.

Negrutiu, I., B. Vyskot, N. Barbacar, S. Georgiev and F. Moneger, 2001 Dioecious plants. A key to early events of sex chromosomes evolution. Plant Physiol. 127: 1418-1424.

Strasburger, E., 1910 Über geschlechtsbestimmende ursachen. Jahrb. Wiss. Bot. 48: 427-520.
Veuskens, J., D. Ye, M. Oliveira, D. D. Ciupercescu, P. Installe et al., 1992 Sex determination in the dioecious Melandrium al bum-androgenetic embryogenesis requires the presence of the X-chromosome. Genome 35: 8-16.

Warmke, H. E., 1946 Sex determination and sex balance in Melandrium. Am. J. Bot. 33: 648-660.

WestergaARD, M., 1940 Studies on cytology and sex determination in polyploid forms of Melandrium album. Dan. Bot. Ark. 10: 1-131.

WestergaARD, M., 1946 Aberrant Y chromosome and sex expression in Melandrium album. Hereditas 32: 419-443.

WestergaARD, M., 1948 The relation between chromosome constitution and sex in the offspring of triploid Melandrium. Hereditas 34: $257-279$.

WestergaARD, M., 1958 The mechanism of sex determination in dioecious flowering plants. Adv. Genet. 9: 217-281.

Winge, O., 1923 On sex chromosomes, sex determination and preponderance of females in some dioecious plants. C. R. Trav. Lab. Carlsberg 15: 1-26.

Communicating editor: D. WEIGEL 